\title{
Pigmented Bowen disease
}

\author{
Linghong Linda Zhou BHSc, Nisha Mistry MD
}

- Cite as: CMAJ 2017 November 27;189:E1462. doi: 10.1503/cmaj.170810

A 64-year-old woman of South Asian descent presented with a forehead lesion that had been slowly enlarging for three years. On examination, a well-demarcated hyperkeratotic thin brown plaque $\left(1.1 \times 1.4 \mathrm{~cm}^{2}\right.$ in size) was noted (Figure 1$)$. A punch biopsy revealed epidermal hyperkeratosis, parakeratosis, irregular acanthosis and atypical heavily pigmented keratinocytes. There was complete loss of polarity of all layers of the epithelium, aside from the basal layer, without evidence of dermal invasion. These features were compatible with pigmented Bowen disease (squamous cell carcinoma in situ).

Pigmented Bowen disease, an uncommon variant constituting less than $2 \%$ of all cases of Bowen disease, typically presents as a slow-growing, flat, hyperpigmented, well-demarcated scaly plaque. ${ }^{1}$ Although it can affect any area of the body, it is most frequently found in those exposed to the sun. ${ }^{1}$ Most cases are asymptomatic, but itching or burning may be present..$^{1}$ Pigmented Bowen disease is most frequently diagnosed in white people over the age of 60 years. Risk factors include fair skin, older age, chronic sun exposure, radiotherapy, arsenic exposure, history of trauma, and infection with human papillomavirus. ${ }^{1}$ The clinical differential diagnosis includes a melanocytic lesion (including melanoma), pigmented basal cell carcinoma, pigmented actinic keratosis, seborrheic keratosis and solar lentigo. ${ }^{2}$ Because the lesions associated with pigmented Bowen disease share many clinical features with other pigmented lesions, dermoscopic findings such as regular brown globules and glomerular vessels in the absence of classic dermoscopic findings of melanocytic lesions have been used to aid diagnosis. ${ }^{3}$ Nonetheless, the dermoscopic features of pigmented Bowen disease are highly variable, and histopathology remains the gold standard for diagnosis. ${ }^{2}$

This case highlights the importance of considering this diagnosis in patients with darker skin types, in whom nonmelanoma skin cancers are less common than in people with lighter skin types. Although treatment is highly successful in most cases, Bowen disease does have the potential to become invasive. ${ }^{3}$ Management options include topical 5-fluorouracil, topical imiquimod, cryotherapy, electrodessication and curettage, laser ablation, photodynamic therapy and surgical excision. ${ }^{4}$

\section{References}

1. Rodrigues MM, Wiziack NC, Chacha JJ, et al. Pigmented Bowen's disease: a case report of an unusual variant. J Bras Patol Med Lab 2015;51:265-7.

2. Cameron A, Rosendahl C, Tschandl P, et al. Dermatoscopy of pigmented Bowen's disease. J Am Acad Dermatol 2010;62:597-604.

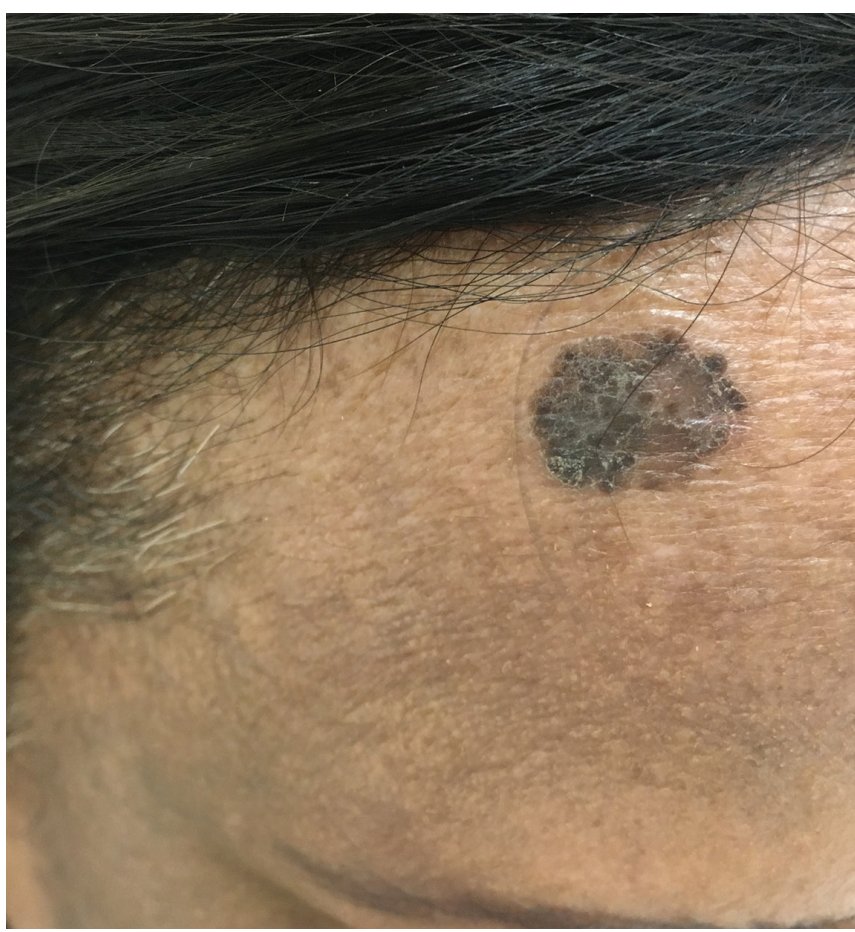

Figure 1: View of a well-demarcated hyperkeratotic thin brown plaque $(1.1 \times$ $1.4 \mathrm{~cm}^{2}$ in size) on the upper right forehead of a 64-year-old woman of South Asian descent.

3. Gutiérrez-Mendoza D, Narro-Llorente R, Karam-Orantes M, et al. Dermoscopy clues in pigmented Bowen's disease. Dermatol Res Pract 2010;2464821.

4. Morton CA, Birnie AJ, Eedy DJ. British Association of Dermatologists' guidelines for the management of squamous cell carcinoma in situ (Bowen's disease) 2014. Br J Dermatol 2014;170:245-60.

Competing interests: Nisha Mistry has received speaker and consultant fees from Valeant Canada. No other competing interests were declared.

This article has been peer reviewed.

The authors have obtained patient consent.

Affiliations: Faculty of Medicine (Zhou), University of Ottawa, Ottawa, Ont.; Division of Dermatology (Mistry), Department of Medicine, University of Toronto, Toronto, Ont.

Correspondence to: Linghong Linda Zhou, Izhou026@uottawa.ca 